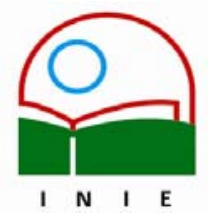

Universidad de Costa Rica

Facultad de Educación

Instituto de Investigación en Educación

ACTUALIDADES INVESTIGATIVAS EN EDUCACION

\title{
DE LO ONTOLÓGICO A LO POLÍTICO SOBRE EL DERECHO DE LA EDUCACIÓN
}

\begin{abstract}
Alfonso Chacón Mata ${ }^{1}$
Resumen: En este trabajo se abordará la naturaleza de la educación, no solo en sus basamanetos más elementales, sino que además, desde una perspectiva política actualizada. Es así, como analizaremos los alcances y desafíos que presenta el derecho a la educación, en toda una amplia gama de manifestaciones: desde una motivación pragmática o vivencial señalando el "deber ser" del fenómeno educativo, hasta su verdadero contraste con lo que "realmente es" a lo interno de los sistemas políticos. Asimismo, ubicaremos el derecho a la educación dentro del entorno internacional a la luz de dos mecanismos yuxtapuestos y si se quiere excluyentes. Por un lado, las opiniones vertidas por el Comité de Derechos Humanos de las Naciones Unidas y lo externado en sus observaciones generales, y por otro lado, la corriente neoconservadurista y globalizadora que visualiza a la educación como una herramienta y no como un fin en si misma. Nos vamos a valer igualmente, de las directrices emanadas políticamente por el Banco Mundial.

Palabras clave: DERECHO A LA EDUCACIÓN/ CARACTERÍSTICAS DE LA EDUCACIÓN/ CONTENIDO DE LA ENSEÑANZA/ EDUCACIÓN Y CONTROL SOCIAL/ OBLIGACIONES DEL ESTADO/ FUNCIÓN REPRODUCTORA DE LA EDUCACIÓN/ NEOCONSERVADURISMO EN EDUCACIÓN/

Abstract: The nature of education will be examined in this work, not only from its most basic foundations, but also from an up-to-date political perspective. In this manner, the scopes and challenges of the right to an education will be analyzed from a broad gamut of manifestations: from a pragmatic or experimental motivation pointing to the "devoir être" of the phenomenon of education, to the contrast with its reality in the context of political systems. In addition, we will place the right to an education within the international environment through the point of view of two juxtaposed and perhaps self-excluding mechanisms: on one side, the opinions of the UNCHR (United Nations Comission for Human Rights) and what this institution has expressed in its general comments; and on the other side, the neoconservative and globalizing trend that sees educations as a tool and not as an end by itself. The politically issued guidelines of the World Bank are also going to be considered in this article.
\end{abstract}

Key words: RIGHT TO AN EDUCATION / FEATURES OF EDUCATION / TEACHING CONTENTS / EDUCATION AND SOCIAL CONTROL / STATE DUTIES / REPRODUCTIVE FUNCTION OF EDUCATION / NEOCONSERVATISM IN EDUCATION.

\footnotetext{
1 Licenciado en Derecho de la Universidad de Costa Rica, Bachiller en Relaciones Internacionales Internacionales de la Universidad Nacional, Costa Rica. Diplomado en Derecho Internacional de los Derechos Humanos de la Universidad Alcalá de Henares, España. Se ha desempeñado como consultor en derechos humanos y laborales para la Fundación Arias, Programa de Normas Internaiconales de la Organización Internacional del Trabajo. Profesor universitario y asesor jurídico de organizaciones laborales vinculadas al Magisterio Nacional.
}

Correo electrónico: achaconm@yahoo.com

Artículo recibido: 25 de agosto, 2005

Aprobado: 21 de noviembre, 2005 


\section{Introducción}

El presente ensayo tiene la finalidad de caracterizar algunos elementos propios de lo que conocemos como el derecho a la educación. Creemos fervientemente que la educación puede ser un factor de cohesión si procura tener en cuenta la diversidad de los individuos y de los grupos humanos y, al mismo tiempo, evita ser a su vez un factor de exclusión social. La educación no es ajena a un proceso, el cual es relatado de la siguiente manera por un autor:

El derecho a la educación tiene el correlativo deber de tener que estudiar las materias que se consideran básicas, elementales e ineludibles para el desarrollo mínimo de la capacidad intelectual de una persona humana. Este nivel varía de acuerdo con el contexto cultural de cada sociedad, pero es fundamental que cada sociedad establezca no sólo sus niveles mínimos para que el mismo lo alcancen todos los ciudadanos, sino que también debe tratar de superarlo. (Valle Labrada, 2000, p. 24)

Ahora bien, de acuerdo con las intenciones y objetivos que pretendemos dilucidar en este ensayo, debemos necesariamente precisar los alcances o postulados básicos que nos motivan a hablar de las "bases ontológicas" de la educación. En primer lugar, conviene observar el término ontología con la intención de tomar un concepto de orden netamente filosófico para aplicarlo en el orden del ejercicio educativo, y al respecto básicamente esta disciplina se refiera a la ciencia del ser, y el adjetivo ontológico se utiliza ordinario para referirnos a todo aquello que tiene relación con el conocimiento del ser (Álvarez, 1987, p.199).

Para nuestros efectos, vamos a tratar de adentrarnos en el ser de la educación, que no es otra cosa más que analizar las dimensiones o basamentos operativos sobre los que este derecho inalienable presta su funcionabilidad. Es por ello que requerimos en los siguientes apartados preguntarnos asuntos básicos tales como éstos: ¿Qué es la educación en su contexto aplicativo? ¿Qué objetivos y finalidades conlleva para los educandos? ¿Qué papel tienen los poderes públicos/políticos en la implementación e instrumentalización del derecho a la educación? ¿Cuál es el grado de reversidad o beligerancia que puede optar el sujeto transformado por el proceso educativo ante la situación vivencial concreta? Sin duda estas inquietudes no son del todo fáciles de evacuar y relacionarían reflexiones mucho más profundas, a las que nos vamos a ver sometidos a lo largo de este trabajo. Sin embargo, es menester derribar los mitos que se tienen sobre el factor neutro de la educación, y más bien 
se debe visualizar detrás de ella, todo un contorno de enseñanzas que van a gestarse en diferentes actitudes ante la vida; sea la indiferencia o el asumir un rol más activo y de agente transformador de la realidad.

Finalmente, deseamos destacar que el carácter de este ensayo es general, por lo que no nos estamos avocando a analizar un modelo educativo en general -como podría ser el costarricense-, sino que lo que pretendemos es sentar criterios de alcance global, que son inherentes al fenómeno educativo cualquiera que sea su naturaleza; sistema u orden sociopolítico. Una vez planteadas las anteriores nociones, procedemos a enfocar lo que entendemos desde nuestra perspectiva, sobre los cánones de la ontología de la educación.

\section{Naturaleza de la Educación: Problemas para su Adecuada Operacionalización y Funcionalidad.}

Empezaremos presentando una definición de lo que implica la educación, no sin antes advertir que todos los términos sujetos a definición, presentan una ineludible realidad. Existen tantas definiciones como autores de las mismas quieran esbozarlas a través de su prisma particular. Esta situación es analizada por Cirigliano, al aducirnos la inevitable controversia que genera la definición de este término: "Sabemos qué se entiende habitualmente por educación, o al menos todos creemos saberlo. Pero apenas intentamos precisar los elementos, las características ocultas bajo ese vocablo, surgen unas primeras dificultades que se van complicando paulatinamente" (Cirigliano, 1989, p. 2)

La educación ha sido definida por algunos autores, en relación con un proceso concreto $^{2}$, o puede ser vista como "una reconstrucción continua de la experiencia" (Hubert, 1959, p. 23). Ambas definiciones involucran al empirismo o a la experiencia, como fuente de explicación ontológica de lo que se entenderá por educación.

Por su parte, la Comisión Internacional de Desarrollo de la Educación de la UNESCO, prefiere hablar de "necesidad" y de "demanda" de educación, en aras de caracterizar este concepto:

Por una parte, la necesidad que tiene una sociedad de disponer de una cantidad dada de ciudadanos instruidos o más instruidos, más o menos específicamente cualificados, a estos o a aquellos niveles, y en tal o cual perspectiva, incluida la perspectiva de cambios estructurales. Esta necesidad emana generalmente en primer lugar de la 
economía; pero también puede ser el hecho de otras múltiples formaciones sociales y del propio Estado, que debe proveer al reclutamiento de sus aparatos y que puede tener también múltiples motivos políticos para desarrollar la educación, siendo el más noble el de elevar el nivel cultural y el nivel de conciencia de la población, con la preocupación de crear las condiciones de una mayor participación democrática de las masas. Por otra parte, la demanda de educación expresada por los individuos, incluidos los padres, demanda cuya manifestación reviste, por adición, el carácter de fenómeno evolutivo (Faure, 1978, p. 77).

El significado más conocido del término "educación" lo identifica con el proceso de instrucción y adiestramiento que se realiza en una institución docente, en una escuela. En los últimos cincuenta años -según Broudy- se ha hecho familiar otro significado, aquel que se refiere al arte, ciencia, o ambos aspectos, de impartir instrucción y adiestramiento. En las universidades y escuelas normales hay departamentos de "educación" dedicados a estudiarla y enseñarla, en este sentido de la palabra (Broudy, 1966, p. 19).

Se ha vinculado también al concepto de educación, con la acción de desarrollar las facultades físicas, intelectuales y morales, siendo un complemento de la instrucción. Es entendido el quehacer educativo, como aquel en el cual una persona desarrolla sus capacidades, para enfrentarse positivamente a un medio social determinado e integrarse a él (MEP, 1993, p. 17). En todo caso, para un autor como Arrién la educación "es considerada un sector clave para el mejoramiento de la calidad de vida de las personas, el progreso físico, económico y social de los países y como una forma de alcanzar un desarrollo humano sostenible" (Arrién, 1997, p. 8).

Existen otras opiniones, como la de Alain Touraine, para quien la educación fue concebida como

...el aprendizaje de la razón contra las pasiones y también como el ingreso en un mundo vasto, gobernado por principios generales, lo que a su vez permite escapar de las imposiciones y de las tradiciones de una comunidad "local" y "esta concepción implicó la autonomía del mundo de los educadores y, en especial, de los funcionarios. (UNESCO, 1984, p. 51)

Sin lugar a dudas, producir un concepto unívoco sobre lo que es la educación, conlleva a una tarea de singular importancia. Pero debido a la delimitación operativa y funcional que 
persigue este trabajo, no seguiremos ahondando sobre las definiciones del caso, y más bien elaboraremos nuestra propia definición. Hemos visto cómo la educación puede ser vista como proceso; como necesidad objetiva de la sociedad; como transmisora de conocimiento, entre otras. De nuestra parte, somos partícipes de concebirla desde una óptica de retroalimentación para la sociedad en su conjunto, y por ello decimos que educación es el conjunto de herramientas cognoscitivas, diseñadas a través de metodologías y sistemas didácticos, que tienen la función de generar en los individuos sujetos a aprender, la transmisión de valores y conocimientos necesarios para obtener un cambio cualitativo en el orden individual, capaz de tener como meta colectiva, una clara incidencia en el desarrollo de la sociedad.

De esta definición, consideramos importante destacar lo siguiente: en primer lugar, entendemos que la educación debe ser un proceso en el que la capacitación esté encaminada a que una persona sea apta para algo. Esta intencionalidad descansa sobre una plataforma instructiva que facilita el aprendizaje y, con ello, nuevas vías en el devenir humano. La educación no solo debe centrarse en proporcionar conocimientos, -crudos, calculados, ensayados- sino que debe transmitir valores a los educandos. Solo así se puede asegurar el primado de máximas universales que sirven para toda época y espacio: justicia, libertad, honestidad, lealtad etc.

Por último, aunque se ha hablado mucho que la educación y el sistema educativo, sirven como mero instrumento ideológico; queremos dejar claro que si bien es cierto que la educación concibe determinados patrones, cuya finalidad radica en fomentar una determinada visión de mundo, su potencial está en la capacidad de construcción histórico/social. No concebimos un proceso educativo en el que se obvie este imperativo, y que por consiguiente, no vaya aparejado para producir cambios dentro del entorno inmediato. Así que desde esta perspectiva, la educación tiene una dimensión social, la cual le da sentido funcional dentro de la colectividad.

\subsection{Contenido de la enseñanza}

Si bien es cierto, hemos aludido diferentes concepciones educativas, en el fondo nos queda una interrogante súbita: ¿cuál debe ser el contenido de una buena enseñanza que permita generar cambios en los seres humanos que se capacitan con ella? Al respecto debemos decir que 
...el aprendizaje a través de la comunicación con los semejantes y de la transmisión deliberada de pautas, técnicas, valores y recuerdos es proceso necesario para llegar a adquirir la plena estatura humana. Para ser hombre no basta con nacer, sino que hay también que aprender. La genética nos predispone a llegar a ser humanos pero sólo por medio de la educación y la convivencia social conseguimos efectivamente serlo. (Savater, 1997, p. 37)

Por su parte, la UNESCO (1996) desarrolla una metodología pedagógica denominada como "Los cuatro pilares de la educación", los cuales son los siguientes: (i) Aprender a conocer $^{3}$; (ii) Aprender a hacer ${ }^{4}$; (iii) Aprender a vivir juntos, aprender a vivir con los demás ${ }^{5}$; (iv) Aprender a ser ${ }^{6}$. Estos pilares son un esfuerzo por cumplir un conjunto de misiones que le son propias a la educación como estructura de aprendizaje, incluso para el resto de toda una vida ${ }^{7}$.

\subsubsection{Características deseables de la educación.}

El objeto de la educación, no suele ser un tema que sea difícil tratar, debido a que presenta diferentes acepciones y prismas de análisis. Sin embargo, a manera de inventario, se hace oportuno en este momento, reseñar una serie de características que pueden adherirse a la educación, siendo que la doctrina dominante llega a considerar como elementos característicos de la educación los siguientes:

1. La educación se remite a la especie humana.

2. La acción sigue siendo una característica determinante, esta acción se ejerce de un sujeto sobre otro.

3. La acción no se agota en sí misma, busca realizar un objetivo.

4. El objetivo no busca la consecución de ciertos bienes materiales, sino más bien los métodos para la consecución de esos bienes materiales (Farrier Brais y otros, 1988, p. 1128).

Sobre el punto último en mención, debe considerarse como la consecución de los bienes por medio de los métodos, como el fin último, sino más bien como una de las consecuencias que permite el conocimiento ya que, las aspiraciones del conocimiento son 
fines últimos que realizan a la persona como tal, y contribuyen al desarrollo de la sociedad como un todo. Existe educación de la inteligencia, no para saber, sino para adquirir los métodos que permitan la conquista del saber, más o menos, el criterio sobre educación está encerrado en las frases anteriores. Es en esencia característico, el conocimiento del método, y no el conocimiento del conocimiento, como fin en sí mismo agotado en un acto, sino continuado hasta el infinito, dependiendo de la capacidad individual del desarrollo del método y su aplicación práctica. (Farrier Brais y otros, 1988, p. 1129).

Para lograr este acometido, se debe impulsar una educación humanista que acentúe naturalmente los objetivos sociales más bien que los individuales. A su vez, este humanismo deberá también extender la enseñanza de la ciencia y del método científico, esforzándose para que todos aprendan a pensar correctamente, más bien que memorizar en forma rutinaria los hechos individuales (Lamont, 1956, p. 249).

Otro ámbito o arista que se ha explorado, como característica necesaria de la educación, es la inmersión de la educación en el desarrollo sostenible. Este tipo de desarrollo se refiere sucintamente a la sostenibilidad de las políticas que tiendan al derecho de mejores condiciones, por lo que el desarrollo sostenible aparece como una extensión natural del derecho a la vida y del derecho a la salud, en cuanto protege la vida humana, tanto en el aspecto de la existencia física y la salud de los seres humanos, como en el de condiciones y calidad de vida dignas (Cancado Trindade, 1994, p. 70). Inicialmente, el Informe Bruntdland empieza a ser un referente sumamente importante en torno a lo que debe entenderse por "desarrollo sostenible", al hablar de este concepto ${ }^{8}$.

Desde la perspectiva de otro autor, como el ex ministro costarricense de Ciencia y Tecnología, Orlando Morales, tenemos que este tipo de desarrollo es definido de la siguiente manera:

El desarrollo sostenible es aquel que presenta la generación de riqueza con equidad social, en un marco de acciones amigables con el ambiente, según consta en documento del Consejo Nacional de Investigaciones de Brasil (CNP) presentado en el seminario que tuvo lugar en la ciudad de Bahía (Estado de Salvador, Brasil, en julio de 1993) sobre ciencia y tecnología para el desarrollo sostenible. 
Si se quiere, el desarrollo sostenible es el conocido desarrollo económico con beneficio social, ahora con una condición adicional, la exigencia del respeto ambiental. (citado por Monge Nájera, 1994, p. 24)

Siguiendo una visión del término netamente de corte ecológico y ético, algunos autores han planteado el desarrollo sostenible, como una relación entre sistemas ecológicos de mayor cobertura y diversidad, en los cuales se afianzan los siguientes elementos:

(i) La vida humana puede continuar "indefinidamente";

(ii) Las individualidades humanas tienen la posibilidad de crecer y multiplicarse;

(iii) Las particularidades culturales pueden sobrevivir;

(iv) Las actividades humanas se procesan dentro de límites que no poseen en peligro la diversidad, complejidad y funciones del sistema ecológico que sirve de base a la vida. (Sepúlveda y Edwards, 1995, p. 11).

Lo cierto del caso radica en que el empleo de nociones pedagógicas de desarrollo sostenible, implica cambiar estilos de vida, costumbres, hábitos que atentan contra el medio ambiente, puesto que los parámetros exigentemente consumistas hacen verdaderamente insostenible nuestras vidas. En este proceso se ha dicho que

...la educación es un instrumento adecuado para el cambio no sólo individual sino también social; no hay duda de que la suma de personas educadas en unos mismos valores posibilita, a la larga, cambios comunitarios y sociales (....) Es necesario que hayan más personas que acepten y valoren la necesidad de sostenibilidad y del desarrollo, en lugar de otras aferradas a los valores causantes del crecimiento permanente; (Colom, 2000, p. 100) .

\subsubsection{Contenido del derecho a la educación y las obligaciones del Estado}

Se han distinguido en relación con la educación, cuatro tipo de obligaciones fundamentales que deben dimanar del Estado: 1-disponibilidad, 2-accesibilidad, 3aceptabilidad y 4- adaptabilidad. 
El Comité de Derechos Económicos, Sociales y Culturales de la Organización de las Naciones Unidas, en su Observación General número 11 sobre el artículo 14 del Pacto Internacional de Derechos Económicos, Sociales y Culturales (PIDESC), ha abordado inicialmente el tema de la disponibilidad, así como los otros temas que nos ocupan. Según la Relatora Especial sobre el Derecho a la Educación

la obligación del Estado de hacer que la educación primaria sea gratuita se asocia a menudo, aunque equivocadamente, con el hecho de que el Estado proporcione dicha educación. La obligación del Estado de ofrecer enseñanza primaria gratuita se cumple en un gran número de países mediante subvenciones a diversos tipos de escuelas primarias. (Programa Internacional de Becas D.H, 2000, p. 344).

La segunda obligación del Estado se refiere a la accesibilidad y plantea que como mínimo, los gobiernos están obligados a garantizar el goce del derecho a la educación, garantizando el acceso de toda persona a las instituciones educativas existentes, en condiciones de igualdad y no discriminación. Sobre la adaptabilidad: normalmente, lo que un niño aprende en la escuela debería estar determinando por sus necesidades futuras como adulto. Sin embargo, la Convención sobre los Derechos del Niño requiere que se asigne importancia primordial a los mejores intereses del niño.

Paul Hunt sugiere un proceso de tres pasos para identificar y utilizar criterios nacionales con el fin de medir los resultados obtenidos por los estados en la esfera del derecho a la educación: primero, seleccionar indicadores claves, segundo, establecer criterios nacionales; y tercero, vigilar los criterios nacionales (Programa Internacional de Becas D.H, 2000, p. 349). Ahora bien, la viabilidad de tales criterios responde en gran medida a la capacidad de recursos que un Estado-nación tenga para darle sostenibilidad, y dentro de la variedad de recursos posibles, su uso adecuado y uniforme es vital para materializar el derecho en estudio. Al respecto el Pacto de Derechos Económicos, Sociales y Culturales (PIDESC) en su artículo segundo, condiciona el cumplimiento de los derechos establecidos en él -y entre estos el de la educación- al máximo de los recursos disponibles de cada Estado. El problema de la atención de tales derechos, con recursos limitados e insuficientes, plantea que los Estados no se escuden en esta disyuntiva como una excusa definitiva e insoslayable. Incluso, se ha sostenido que el disfrute de ciertos DESC, no está condicionado a la progresividad y que su satisfacción puede ser inmediata, -como es el caso de la libertad sindical o la libertad de los padres para escoger la educación de sus hijos-, sin 
que pueda alegarse la inexistencia de recursos estatales necesarios para dar cumplimiento a estas obligaciones (Bolivar, 1996, p. 39).

El artículo 2.1 del PIDESC requiere que cada Estado disponga de medidas, según el máximo de sus recursos disponibles, en aras de ir implementando la plena realización de los derechos reconocidos en esta materia. Este máximo de recursos o provisión de recursos, requiere que los Estados tomen inmediatamente medidas posibles a su alcance y otras medidas en forma expedita, si no están tan a su disposición (Kunnerman, 1996, p. 3). Para Robert E. Robertson, el artículo segundo del PIDESC recuerda a los Estados la obligación de "tomar medidas... según el máximo de sus recursos disponibles", por lo que en ese contexto, "medidas" representa acciones específicas y "recursos" representa el grado de satisfacción con que los derechos son satisfechos. Por ejemplo: en el campo de la educación, la ley que prescribe la educación libre es una medida, escuelas, maestros y libros son recursos". (Robertson, 1994, p. 695)

Los recursos pueden ser del más diverso orden, (humanos, tecnológicos, financieros, etc.), pero lo que es realmente imposible es hablar de un recurso sugerido como principal indicador, pues si pensamos en los gastos militares como ejemplo, nos encontramos con que en 1991 los países desarrollados gastaron un 3,6\% de su producto nacional bruto y en salud un $5,3 \%$. En cambio los países subdesarrollados gastaron un 1,6\% en salud y el doble en gastos militares, 3,8\% (Robertson, 1994, p. 711).

Volviendo a retomar a Lamont, tenemos que el autor enuncia lo siguiente, Una sociedad humanista invertirá en la educación y en la cultura general sumas equivalentes a las que en la actualidad destinan los gobiernos para armamentos y para la guerra. En especial, las escuelas y colegios, universidades e institutos de investigación, con sus perpetuas dificultades financieras, se beneficiaran con recursos económicos fuertemente aumentados. Finalmente, las instituciones educativas podrán construir edificios adecuados, y emplear con salarios generosos al personal docente, y desaparecerá la aglomeración corriente con las ventajas que se derivan de la atención individual para todos los tipos de estudiantes. (Lamont, 1956, p. 249)

Ahora bien, en referencia con las obligaciones del Estado en el campo del derecho a la educación, éstas son definidas por el Comité de Derechos Económicos, Sociales y Culturales 
en el marco de la Observación General No 13 -que incluso vamos a retomar más adelante ${ }^{10}$, de la siguiente manera:

46. El derecho a la educación, como todos los derechos humanos, impone tres tipos o niveles de obligaciones a los Estados Partes: las obligaciones de respetar, de proteger y de cumplir. A su vez, la obligación de cumplir consta de la obligación de facilitar y la obligación de proveer.

47. La obligación de respetar exige que los Estados Partes eviten las medidas que obstaculicen o impidan el disfrute del derecho a la educación. La obligación de proteger impone a los Estados Partes adoptar medidas que eviten que el derecho a la educación sea obstaculizado por terceros. La de dar cumplimiento (facilitar) exige que los Estados adopten medidas positivas que permitan a individuos y comunidades disfrutar del derecho a la educación y les presten asistencia. Por último, los Estados Partes tienen la obligación de dar cumplimiento (facilitar el) al derecho a la educación. Como norma general, los Estados Partes están obligados a dar cumplimiento a (facilitar) un derecho concreto del Pacto cada vez que un individuo o grupo no puede, por razones ajenas a su voluntad, poner en práctica el derecho por sí mismo con los recursos a su disposición. No obstante, el alcance de esta obligación está supeditado siempre al texto del Pacto. (Organización de las Naciones Unidas, 2001, p. 92).

El párrafo 54 de la citada observación general, aduce que los Estados Partes o suscriptores del Pacto Internacional de Derechos Económicos, Sociales y Culturales, tienen la obligación de establecer "las normas mínimas... en materia de enseñanza" que deben cumplir todas las instituciones de enseñanza privadas establecidas con arreglo a los párrafos 3 y 4 del artículo $13^{11}$. Es interesante destacar que la alusión a las normas mínimas o también denominado como contenido mínimo, es una construcción verificatoria dictada por el mismo Comité de DESC ${ }^{12}$.

En todo caso, a manera de corolario en este asunto, podemos concluir que las teorías y la investigación sobre el Estado muestran que no se puede separar un análisis del sistema educativo de algún análisis explícito o implícito del papel, propósito y funcionamiento del Gobierno. Particularmente durante el siglo XX, la educación se ha ido convirtiendo cada vez más en una función de Estado. Los sistemas y las prácticas educativas están patrocinados, ordenados, organizados y certificados por el Estado (Torres, 2001, p. 27). Precisamente esta función ideologizadora de la entidad estatal, tiende a producir y a mostrar efectos 
propios de intromisión o imposición, de un determinado modelo o visión de mundo. Nos referiremos a este tema en las líneas siguientes.

\subsection{Finalidad del proceso cognoscitivo y el medio cultural/linguístico}

Sin duda alguna, la labor de la educación en un ser humano es de primer orden. Primero que nada, perfila a los hombres y mujeres que deseamos, el prototipo de ciudadano capaz de utilizar todo aquel arsenal de conocimientos que le proporciona el saber mismo, en función de obtener una apreciación más sensible e inteligente de la vida. Es por esta razón que la educación como fuente de acceso a una cultura, permite el tránsito de un "hombre viejo" a un "hombre de ahora", que es en última instancia, el ideal por realizar. Se conforma una acción moldeadora, similar a la del alfarero y la arcilla, hasta llegar a un significado igual al de la palabra alemana bildung (formación, configuración), vocablo que designa el modo más intuitivo de la esencia de la educación en el sentido griego y platónico. En la antigüedad, nos encontramos casos como el referente, donde el principio espiritual de los griegos no es el individualismo, sino el "humanismo", y este humanismo significó la educación del hombre de acuerdo con la verdadera forma humana, con su auténtico ser (Malavassi, 1973, p. 15).

Ahora, esta noción se debe referenciar con dos variables que se tornan de trascendencia vital, el medio cultural y el aspecto lingüístico. Si nos referimos a la cultura y el desarrollo cognitivo tenemos que esta situación encierra la siguiente situación: ¿Qué significa, intelectualmente, crecer en un determinado medio cultural y no en otro? Evidentemente, se trata de la vieja cuestión de cómo se relacionan la herencia y el ambiente en este caso, de qué manera depende el desarrollo intelectual de las influencias externas. No es nueva la idea de que las diferencias culturales producen formas de pensar distintas (Bruner, 1987, p. 35). Este es un tema constante en antropología, y en este mismo orden de ideas, nos encontramos con que la cultura como manifestación concreta del hombre, ha sido vista por la antropología con especial interés. Edward B. Taylor, en el siglo pasado (1871), escribe que "La cultura o civilización, en sentido etnográfico amplio, es aquel todo complejo que incluye el conocimiento, las creencias, el arte, la moral, el derecho, las costumbres y cualesquiera otros hábitos y capacidades adquiridas por el hombre en cuanto miembro de la sociedad" (citado por Kahn, 1976, p. 23). Si bien la tendencia general en los Estados Unidos ha sido la de reducir la cultura a un conjunto de reglas relativas a determinados sistemas 
conceptuales y limitar la antropología al descubierto de dichas reglas y la tendencia en Gran Bretaña ha sido la de ignorar la cultura, en favor de los estudios de estructura social, han existido varias tentativas de volver a una definición más amplia del campo de aplicación de la antropología (Kahn, 1976, p. 23).

Malinoski considera que el hombre varía en dos aspectos; en forma física y en herencia social o cultura. Además agrega:

La palabra cultura se utiliza a veces como sinónimo de civilización, pero es mejor utilizar los dos términos distinguiéndolos, reservando civilización para un aspecto especial de las culturas más avanzadas. La cultura incluye los artefactos, bienes, procedimientos técnicos, ideas, hábitos y valores heredados. La organización social no puede comprenderse verdaderamente excepto como una parte de la cultura; y todas las líneas especiales de investigación relativas a las actividades humanas, los agrupamientos humanos y las ideas y creencias humanas se fertilizan unas a otras en el estudio comparativo de la cultura (citado por Kahn, 1976, p. 85).

Por su parte, White ha admitido que no existe un consenso válido y uniforme entre los antropólogos, puesto que para unos, la cultura es solamente una conducta aprendida, o que se compone tan solo de hachas y vasijas de cerámica; otros son de la opinión de que ningún objeto material puede ser considerado cultura; o que la cultura existe solamente en el intelecto (White, 1983, p. 129).

Se debe tener presente que las culturas son autónomas, independientes unas de otras e incomunicables. Para ciertos autores, la idea antropológica de que "todo es cultura" coloca las realizaciones humanas en el mismo nivel, de lo cual se deduce que todas las culturas son válidas, por tanto, desde la perspectiva relativista, se debe mantener la total neutralidad valorativa, pues no existe ninguna ética universal desde la cual juzgarlas (Carvajal, 1998, p.12).

De acuerdo con lo anteriormente expuesto, el proceso cognoscitivo estará ligado al medio cultural en el que se desenvuelva el individuo. Sin embargo, el quid del asunto estaría en descifrar incógnitas como éstas: ¿en qué parte de la cultura deberían encontrarse diferencias en los procesos de pensamiento? Los lingüistas antropológicos surgieron una respuesta concreta: donde hay diferencias lingüísticas puede (¿o debe?) haber diferencias cognitivas (Bruner, 1987, p. 38). Es así cómo según lo externado por Bruner, se presenta la 
segunda limitación cultural, que es el lenguaje, lo que implica severas diferencias hablar una lengua en lugar de otra y como esta correlación afecta o privilegia el desarrollo del conocimiento a través de la educación (Bruner, 1987, pp. 48-49).

Nos detenemos en este tópico de la lengua, puesto que ésta presenta diferentes particularidades, de acuerdo con el contexto histórico y social. Es así, cómo a manera de ilustración, tenemos que en el pueblo de lapón en las regiones subárticas de Escandinavia, sus moradores luchan contra la inclemencia climática de la naturaleza y debido a esta realidad, emplean once palabras para los diferentes grados de intensidad del frío; veintiuna para la nieve en sus diferentes estados de agregación; veinte para las diversas clases de hielo y veintiséis verbos para expresar formas y modos de "congelarse" y "derretirse" (Schulte-Herbrüggen,1985, p. 22). En el fondo, la función del lenguaje no le sirve solamente al hombre para expresar alguna cosa, "sino también para expresarse a sí mismo" (Salinas, 1974, p. 7).

Por otra parte, la cuestión del pluralismo cultural y lingüístico se plantea también en el caso de las poblaciones autóctonas o en el de los grupos migrantes, para los cuales se trata de encontrar un equilibrio, entre el afán de una integración satisfactoria y el arraigo en la cultura de origen. En todo caso, el reto deviene en que toda política educativa debe, por tanto, estar en condiciones de responder a un reto fundamental que convierte esa reivindicación legítima, en un factor de cohesión social.

\section{Educación y cambio humano/social: ¿avance o estatismo?}

Es conveniente destacar la ratio o finalidad esencial que conlleva la educación. Al respecto, debemos decir inicialmente que la educación se constituye en el vehículo de cambio en una sociedad y sus raíces etimológicas vienen del latín "educere" que, literalmente, significa conducir de o desde, por lo que en síntesis tenemos que se trata de conducir al hombre. Por consiguiente, en este caso

...conducir desde no tiene sentido sin el adonde hacia que se conduce. Por lo tanto, con lógica elemental, el conducir de la educación presupone des términos: el término a quo o punto de partida desde el que se conduce y el otro necesario término ad quem, que constituye la meta de la educación. La conducción, en que la educación consiste, no es una conducción de un lugar geográfico a otro. Lo que la educación se propone 
es cambiar al hombre, llevarle de un estado a otro, conseguir nada más que una nueva manera de ser. (Álvarez, 1989, p. 15)

Es menester reparar en la función socializadora de la educación, desde el punto de vista de influencia colectiva, capaz de "mantener" o "transformar" un orden establecido Hablaremos brevemente de connotaciones que se manejan hoy por los teóricos y estudiosos en el campo educativo: control social y función reproductora de la educación serán situaciones que observaremos seguidamente

\subsection{Control social de la educación.}

La educación puede ser vista desde diferentes perspectivas; como un instrumento de los aparatos ideológicos del Estado (Althusser, 1987, pp. 35-37); como un elemento superestructural del mismo que refleja un sistema de dominación ${ }^{13}$ o, simplemente, como un mecanismo diseñado para adoctrinar a la población que accesa al sistema educativo.

Como todo proceso estructurado en el orden social, nos encontramos con que la educación presenta claros objetivos, pues tal como lo dice Beatriz Fainholk:

EDUCAR, en la práctica se convierte en sinónimo de formar o dirigir. No se puede formar sin un modelo preconcebido, ni se puede dirigir sin poseer alguna indicación de los objetivos que se desea alcanzar. De ahí que durante siglos la educación consistiera en transmitir a las generaciones jóvenes los patrones de conducta conocidos, aprobados y compartidos por los grupos que conformaban la estructura social (...). (1979, p. 57)

La misma autora profundiza sobre el término "control social", y, al respecto, nos dice que el mismo

...no es nuevo para los sociólogos ni para los educadores. Ya Comte, como luego Durkeim, se preocuparon por el problema del "orden", estudiando los símbolos, valores, ideas, etc., y el papel determinante que éstos desempeñaban en la continuidad y supervivencia de los variados tipos de sociedades. El término "control social" fue usado por primera vez por Herbert Spencer en 1893. En inglés se le acepta como fuerza, dominación, autoridad, mientras que otros idiomas europeos lo entienden como fiscalización, inspección, ceremonial, etc. (Fainholk, 1979, p. 57). 


\subsubsection{Efecto de la educación en el statu/quo.}

Se hace innegable menospreciar el impacto de la educación en los cambios históricos y sociales, que se han suscitado en el devenir de la humanidad. Si nos remontamos a la influencia del factor cognosctivo/educativo operado en el siglo XVIII, y el consecuente cambio generado en el interior de los Estados-Nación de Europa, nos encontramos con que el Movimiento llustracionista fue decisivo para la crítica y la progresiva sustitución de la educación clásica, ya discutida en siglos anteriores por autores como Rabeleis o Montaigne. Todavía a principios del citado siglo, se mantenía la tradicional enseñanza religiosa en las escuelas, impulsada por los jesuitas, en la que privaba el estudio de la moral católica, frente a la razón, por lo que la instrucción estaba orientada a la formación del juicio y de las costumbres y, sobre todo, a potenciar la fe en los niños (Peces-Barba Martínez y otros, 2002, p. 13).

Para devolver a la educación su lugar central en la dinámica social, conviene en primer lugar salvaguardar su función de crisol, luchando contra todas las formas de exclusión. Para la Comisión Internacional sobre la Educación para el siglo XXI de la UNESCO,

La enseñanza del pluralismo no sólo es protección contra las violencias sino, además, un principio activo de enriquecimiento cultural y cívico de las sociedades contemporáneas. Entre el universalismo abstracto y reductor y el relativismo para el cual no hay exigencia superior, más allá del horizonte de cada cultura particular, conviene afirmar, a la vez, el derecho a la diferencia y la apertura a lo universal. (Unesco, 1996, p. 56).

Sin embargo, este carácter pluralista o abierto que debe tener por antonomasia la educación, no siempre se suscita como tal. Para Adam Curle, la educación puede ser partícipe directa de la legitimación de un determinado estado de desarrollo en una sociedad. Así tenemos que para el citado autor, la situación es descrita de la siguiente manera:

La enseñanza interviene en la creación de este tipo de desarrollo y lo hace por dos caminos distintos. En primer lugar, adoctrina en una actitud ideológica que acepta el sistema que provoca estos síntomas espantosos. Claro que a la mayoría de las gentes no les gustan los síntomas, pero no alcanzan a ver las relaciones que los producen: si lo alcanzasen tendrían que rechazar las recompensas que reciben del sistema, sobre el cual se basa la abundancia tranquilizadora de sus vidas. En segundo lugar la 
enseñanza produce un efecto contrario; retiene ciertos sectores de la población, les impide entrar en la competición por medio de sus mejores miembros, les mantiene pobres y útiles a la clase selecta, a la élite, incluso cuando ésta es la mayoría. (Curle, 1977, p. 15).

La aseveración expuesta nos permite intuir que la aceptación tácita del orden establecido, se ve nutrida por un modelo educativo que tiende a ser en primer lugar conformista, pues se adopta una postura indiferente o insensata, en la que lo establecido es real y no factible al cuestionamiento o cambio. A la vez, el mismo modelo necesita ser por naturaleza altamente selectivo, ya que solo un grupo menor de los ciudadanos puede terminar una educación completa. El resto de la población necesita estar en la marginalidad, no asumiendo posiciones ni cuestionamientos, siendo útiles a una minoría preparada y que lidera todo. De ahí que el sistema lejos de ser integrado, tiende a la fragmentación de clases y conocimientos, en forma sumamente evidente (Duverger, 1976, pp. 224-225).

De esta manera, la relación entre educación y economía es ineludible, y de esta simbiosis se han enumerado los aspectos básicos de esa conjunción:

- La educación reproduce las relaciones económicas o de producción que definen el tipo de actividad de cada sociedad.

- La educación transmite y difunde conocimientos y tecnologías que acrecientan el desarrollo económico, lo que establece una relación directa entre ambas fuerzas.

- La educación es un factor de producción, en la medida cómo prepara los recursos humanos calificados para el crecimiento económico, que en las sociedades contemporáneas exige determinados niveles educativos a los miembros de la colectividad para insertarse con éxito en el sistema productivo.

- La educación amplía y diversifica las necesidades humanas, incluidas las de consumo, al promover la movilidad socioeconómica (Dengo, 1995, p. 42).

La anterior conjunción nos pone en la evidencia de abordar la demanda de una educación con fines económicos y cómo debería ser ésta posibilidad. Al respecto se ha sostenido que las comparaciones internacionales ponen de relieve la importancia del capital humano para la productividad y, por consiguiente, la inversión en educación. Las relaciones 
entre el ritmo del progreso técnico y la calidad de la intervención humana se tornan cada vez más visibles, así como la necesidad de formar agentes económicos capaces de utilizar las nuevas tecnologías y manifestar un comportamiento innovador. Se exigen nuevas aptitudes y los sistemas educativos deben responder a esta necesidad no sólo garantizando los años estrictamente necesarios de escolaridad o de formación profesional, sino formando científicos, personal innovador y tecnólogos de alto nivel (UNESCO, 1996, pp. 70-71).

Ahora bien, hay que realizar un par de digresiones a esta posibilidad de educación economicista, con la finalidad de abordar las situaciones que estimamos oportuno reseñar. En primer lugar, la estructura de relaciones de producción inherente al sistema económico internacional en la actualidad, implica que existan países con alto grado de desarrollo tecnológico y otros que solo aportan su contribución, desde el aprovisionamiento de materias primas e insumos que coadyuven en el anterior desarrollo.

En segundo lugar, la responsabilidad fundamental de elaborar y administrar sus propios programas para satisfacer las necesidades educativas de su población, incumbe en definitiva a cada país. La asistencia internacional podría aplicarse a la capacitación y el desarrollo institucional en las esferas del acopio de datos, el análisis, la investigación, la innovación tecnológica y las metodologías de la educación. El problema en el fondo, consiste en que estamos gestando en el seno de nuestras sociedades, lo que Ortega y Gasset llamaba la barbarie del "especialismo", al concebir "hombres-masa", producidos por la democracia liberal y la técnica:

Pues bien (...) resulta que el hombre de ciencia actual es el prototipo del hombre-masa. Y no por casualidad, ni por defecto unipersonal de cada hombre de ciencia, sino porque la ciencia misma -raíz de la civilización- lo convierte automáticamente en hombre-masa; es decir, hace de él un primitivo, un bárbaro moderno. (Ortega y Gasset, 1959, p. 84)

\subsubsection{Función reproductora de la educación.}

Por último, nos interesa referirnos a una explicación que se ha suscitado con respecto a cómo la educación sirve para determinar una visión de la realidad muy concreta. Reproducimos lo dicho por la UNESCO a continuación: 
Reproducción y renovación: la educación puede ejercer tanto una como otra de estas dos funciones.

Se le tacha fácilmente de inmovilismo. No es seguramente la única institución a la que le dirige este tipo de reproche. De hecho, una de sus funciones esenciales es la función de repetición: repetir a cada generación el saber que la generación precedente poseía ya de sus antepasados. Por lo tanto están dentro del orden de las cosas el que una de las tareas de los sistemas educativos sea (o al menos haya sido hasta ahora), el transmitir los valores del pasado; ésta es la razón de que tiendan por naturaleza a constituirse en sistema cerrado en el tiempo y en el espacio, preocupados por su propia existencia y por su propio éxito; por tanto su tendencia natural les inclina a la introspección. A este respecto, la educación concurre objetivamente a consolidar las estructuras existentes, a formar individuos aptos para vivir en la sociedad tal como es. Bajo este ángulo, y sin dar al término un sentido peyorativo, la educación es conservadora por naturaleza. (Faure, 1978, p. 116)

Para López Avendaño, la educación puede ser enfocada como actor de cambio o de reproducción cultural:

De acuerdo con diversos autores, la educación como institución formal, más que factor de cambio cultural y social, juega el papel de reproductora del sistema existente. Esto se afirma por el papel que le corresponde como transmisora de los mecanismos sociales, la transmisión de los valores y otros elementos culturales a las nuevas generaciones.

A la educación corresponde transmitir valores, dotar de los conocimientos y destrezas necesarias para ocupar los diversos cargos de la estructura de la sociedad, así como para la vida en sociedad. Por otra parte, al contribuir a la consolidación del tipo de sociedad vigente en el momento, la educación se presenta controlada y organizada por los grupos que detentan el poder político y social. En este sentido, cabe recordar a Durkheim cuando asevera que cada sociedad construye la educación que necesita para su existencia. (López, 1997, pp. 85-86)

Siguiendo con este debate, en relación con la función reproductora de la educación, nos encontramos con el ineludible hecho de que una teoría de la instrucción, es una teoría política en el sentido de que se deriva del consenso que se refiere a la distribución del poder 
dentro de la sociedad: ¿a quién se educará? y ¿qué roles se deben cumplir? BRUNER al respecto nos dice que

En el mismo sentido, la teoría pedagógica surge, seguramente, de una concepción de la economía, porque cuando hay una división del trabajo dentro de una sociedad, e intercambio de bienes y servicios, por riqueza y prestigio, son fundamentales las cuestiones como se educa, a cuántos y con que limitaciones en el uso de recursos. El psicólogo o el educador que formule una teoría pedagógica sin tener en cuenta el entorno político, económico y social del proceso educativo se arriesga a caer en la trivialidad, y merece ser ignorado, tanto en la comunidad como en la clase. (Bruner, 1987, p. 112)

Nos encontramos entonces, con la ineludible realidad de que el discurso económico ha llegado a dominar el panorama educativo, al punto de que el discurso propiamente educativo (el de la escuela y sistema educativo; el de las relaciones y los procesos de enseñanza / aprendizaje en el aula; pedagogía; educación como tal) y sus ejecutores (profesores, pedagogos, especialistas en educación y áreas afines), apenas tienen cabida mínima en el discurso educativo contemporáneo. Tanto en el nivel nacional como internacional, la política educativa se encuentra general y principalmente, en manos de economistas o de profesionales vinculados a la educación, desde la economía, más que desde el currículo o la pedagogía (Torres, 1997, p. 96).

La anterior situación nos lleva a una verdad de Perogrullo: buena parte de quienes opinan sobre lo que hay que hacer o no hacer en el campo educativo, y que es más, tienen poder decisorio; carecen del conocimiento y la experiencia necesarios para lidiar con los campos sobre los que se pronuncian y deciden: educación básica, enseñanza y aprendizaje en el aula, aprendizaje infantil, capacitación docente, desarrollo y reforma curricular entre otros tópicos de este profuso quehacer educativo. Pocos de ellos han estado en un aula impartiendo lecciones, o pocos saben las penurias y vicisitudes que se viven en el día a día de la población docente, por aspectos tales como sus salarios, material docente, falta de equipos adecuados para impartir una aceptable calidad de enseñanza etc. El peligro de todo este panorama estriba en que la educación es analizada con criterios propios de mercado, como si fuese una empresa pura y simple. 
Entonces, en el fondo la pregunta que salta a la palestra, después de todo lo anteriormente expuesto es la siguiente: ¿Qué tipo de educación estamos dando en nuestro sistema educativo? ¿Hacia donde estamos enfilando el conocimiento y su conducción de estilo de desarrollo? ¿Qué peligros atañen a una educación visualizada en forma mercantilista? Sobre esas inquietudes, vamos a ahondar en los acápites que vienen a continuación.

\subsection{La educación y su permeabilidad a las corrientes neoconservaduristas}

No podríamos hablar en este apartado de la temática que deseamos reseñar, sin antes presentar como antesala el escenario político y social, que concibe las corrientes neoconservaduristas en todo el continente americano. Al respecto, un Informe Regional sobre el estado de la educación y los principales indicadores socioeconómicos, fue claro en determinar que en América Latina, las décadas de los sesenta y setenta se caracterizaron por el crecimiento del Producto Interno Bruto (PIB) por habitante a un ritmo anual medio de 2,5 y $3,5 \%$, respectivamente, mientras que las décadas de los ochenta y noventa fueron marcadas por una crisis económica generalizada. Los ingresos reales por habitante disminuyeron en la década de los ochenta (que suele calificarse en la región como la "década perdida") y solamente experimentaron un crecimiento relativo en el período comprendido entre 1990 y 1999, en una proporción anual media ligeramente superior al 1\%.

Al controlar la inflación y restablecer una pauta duradera de crecimiento, todos esos países, incluido Cuba, han liberalizado en diverso grado su economía. Esencialmente, esas reformas, cuya ejecución ha sido fuente de considerables controversias, entrañan un control fiscal y financiero más riguroso, una mayor receptividad a las inversiones extranjeras, una mayor flexibilidad en la regulación del mercado de trabajo y la ejecución de grandes programas de privatización. La incorporación de esas economías al mercado internacional, ha generado la introducción de cambios significativos en los sistemas productivos y en la organización del trabajo. Todo esto, sumado a la supresión de puestos de trabajo en gran escala en el sector público como parte de la reestructuración, ha provocado una fuerte disminución de la demanda de mano de obra en el sector formal, sobre todo, en el caso de los trabajadores no calificados, con la consiguiente mayor importancia del sector informal, como parte integrada a la economía en su conjunto (UNESCO, 2000, pp 11-12). 


\subsubsection{El Neoconservadurismo}

Esta doctrina se ha erguido como un pensamiento desarrollado en medios académicos y políticos de Estados Unidos de América y que se expande a casi todo el Tercer Mundo. En síntesis, el neoconservadurismo vislumbra la causa de la crisis económica por la que atraviesan los países occidentales, debido a dos factores: el Estado y las demandas populares (Soto, 1985, p. 81). Sencillamente, los acólitos de esta doctrina enuncian que, entre los anteriores elementos existe una estrecha relación. El aparato estatal se ha expandido, debido a la atomización de las demandas populares: ante cada petición, el Estado crea una nueva institución, lo cual provoca un aumento en los gastos fiscales que se traduce en la absorción de recursos crediticios, emisión inorgánica, inflación, etc. (Soto, 1985, p. 81).

El anterior espectro provoca que en el ámbito político, se suscite una "ingobernabilidad" y una "crisis de autoridad". Con respecto al primer efecto, es común en estos últimos tiempos suscitar una serie de debates sobre el fenómeno de la gobernabilidad e ingobernabilidad, y sus implicaciones en la sociedad civil. Sin embargo, para los efectos de este apartado, apostaremos solamente al análisis de la gobernabilidad, como concepto alusivo que varía en el espacio y tiempo, y "cuya definición e incluso presencia en el debate público, depende de la percepción que una sociedad tenga en cada etapa acerca de cuán organizado o inseguro es su proceso de gobierno, y de los factores de los cuales depende ese proceso" (Tomassini, 1993, p. 23).

Hemos caracterizado en otra ocasión, que la gobernabilidad, como espectro político, se mide en el entorno de un sistema abierto, en el cual interactúa una serie de peticiones e insumos, -imputs u outputs- que se procesan a través de mecanismos, tales como la memoria social, los recursos con que cuenta el Estado y la evaluación que realiza de ellos; y cuyo resultado final es la percepción estatal sobre la realidad (Chacón, 1996, p.13).

Con base en lo anteriormente expuesto, dijimos también que

Esta dinámica inteligible del Estado, como sujeto principal de decisiones que afectan a las colectividades, supone una constante búsqueda de estabilidad del sistema político. En principio, se podría decir que el presupuesto real sobre el que debe apoyarse la gobernabilidad lo constituye la estabilidad. El ejercicio de la actividad gubernativa supone un manejo hábil que busque aliviar o disimular las contradicciones entre las 
necesidades básicas crecientes versus recursos reducidos del sistema, para hacerle frente a tales requerimientos; o de los grupos de presión versus incapacidad del sistema político para satisfacer los principales intereses colectivos existentes. (Chacón, 1996, p. 13)

Sin embargo, con absoluta certeza podría decirse que con respecto a la estabilidad necesitada, la misma se debate en el marco de una serie de variables contemporáneas. Entre otras, podemos aludir al efecto que tiene el libre mercado, y la era de la información. También, podríamos ensayar algunas definiciones de lo que entendemos por "ingobernabilidad". Este concepto podría apreciarse de muchas formas, pero lo más elocuente es sin duda alguna, entender a la Ingobernabilidad como el antónimo de Gobernabilidad. Nos interesa lejos de ahondar en aspectos etimológicos, comprender a la ingobernabilidad, como una realidad objetiva y evidente, capaz de ser comprendida no solo como la "ausencia de...", sino que además de eso, el reflejo de situaciones límite que atentan contra la sana convivencia y ponen en peligro al sistema político como un todo.

Con respecto a la denominada crisis de autoridad, desde la óptica del neoconservadurismo, esta denominada crisis se manifiesta en los siguientes aspectos: i) el Estado no tiene capacidad de satisfacer todas las demandas populares; ii) el Gobierno que detenta en ese momento el poder estatal se ve obligado -ante la presión de los sectores medios y obreros- a pasar por alto algunas normas constitucionales, con lo cual se va diluyendo poco a poco el "Estado de Derecho" y iii) ante esta atomización de peticiones, se produce un "impasse" en la toma de decisiones (los grupos de presión paralizan las ramas ejecutiva y legislativa) (Soto, 1985, p. 88).

\subsubsection{Educación "neoconservadurizada" en Costa Rica}

En una publicación efectuada por Carnoy y Torres que se publicó en 1994, observaron al estudiar el caso de la educación en Costa Rica, durante los años ochenta, patrones neoconservadores en sus planes de estudio, los libros de texto y la enseñanza, como cambios en la división internacional del trabajo y la dinámica del mercado. Los políticos costarricenses trataron de resolver el problema de descenso en la matrícula, tasas de deserción escolar cada vez más altas y maestros insatisfechos que culpan a los maestros públicamente de una educación "mediocre” (Torres, 2001, p. 67). 
Ahora bien, volviendo a los patrones de corte neoconservadurista que nos relata el autor y sobre todo, apegándose a la división internacional del trabajo como elemento coadyuvante para dicha teoría, esta división obedece, esencialmente, a la crisis de valorización y acumulación de capital (paro estructural) en los países industrializados. Al respecto, se ha dicho lo siguiente:

A raíz del estancamiento que muestra la reproducción del capital en los países desarrollados, que se manifiesta en la paralización de la tasa de inversión al interior de los mismos, las grandes empresas vuelven su mirada hacia el principal recurso que tiene el Tercer Mundo: un enorme ejército industrial de reserva, de mano de obra barata; la reacción no se hace esperar: las inversiones en los países subdesarrollados muestra una tendencia al crecimiento. En este proceso de operación del capital extranjero en la periferia -a través de la "industria" de maquila en zonas francas- son necesarias tres condiciones: abundante fuerza de trabajo, fragmentación del proceso productivo que permite que la mayor parte de sus fases pueda ser realizada por mano de obra muy poco calificada, y desarrollo de la tecnología de los transportes y comunicaciones para realizar producciones completas o parciales sin importar la distancia y ubicación geográfica. (Soto, 1985, p. 89)

La anterior aseveración de la educación al servicio del neoconservadurismo en Costa Rica, implica necesariamente que los lineamientos educativos están encaminados para apostar modelos de desarrollo económico de países maquileros, como panacea del confort y ubicación natural dentro del sistema de relaciones económicas vigentes. Sobre este hecho vamos seguidamente a ocuparnos con la visión que ostentan en la actualidad los entes de ayuda internacional, como es el caso del Banco Mundial y su visión sobre el concepto de educación.

\subsubsection{El Banco Mundial y su papel en la educación}

El Banco Mundial es un grupo formado por cuatro instituciones : el Banco Internacional de Reconstrucción y Fomento (BIRF), establecido en 1945 y que fue la institución original ; la Corporación Financiera Internacional (CFI) creada en 1956 ; la Asociación Internacional de Fomento (AIF), establecida en 1960, y el Organismo Multilateral de Garantía de Inversiones (OMGI), creado en 1988. Las cuatro instituciones tienen por objetivo común el de "reducir la 
pobreza y mejorar los niveles de vida mediante la promoción del crecimiento y el desarrollo económico sostenibles" (Organización de las Naciones Unidas, 1995, p. 303).

Se han desarrollado por parte de los historiadores del banco y en sus mismos documentos oficiales, tres fases evolutivas del modus operandi del mismo: en la primera etapa, 1946-1962, bajo la presidencia de Eugene Black, el énfasis era puesto sobre proyectos infraestructurales que no atraían el interés del capital privado y que, como preparación al ingreso del inversionista privado, era una tarea que se descargaba en el Estado. La segunda etapa, 1962-1968, siendo presidente del banco George Woods, se considera muchas veces como una transición en la que el énfasis se habría desplazado, de la prevalencia anterior de proyectos infraestructurales a inversiones más directamente productivas en la agricultura y la industria. Robert S.Mc Namara, especialista en problemas de la seguridad, asume la presidencia del Banco Mundial, que se conoce como la tercera etapa, desde 1968 en adelante (Asmann, 1980, pp. 15-17). Sin embargo, esta tercera etapa se encuentra superada, con la que vive actualmente esta dependencia del sistema internacional, ya que el Banco Mundial -en adelante BM-, ha pasado a ser, en los últimos años, el organismo con mayor viabilidad en el panorama educativo mundial, convirtiéndose en la principal consultora educativa en el ámbito mundial (Coraggio, 1997, p. 77).

El BM tiene una propuesta articulada y estructurada para mejorar el acceso, la equidad y la calidad de los sistemas escolares, particularmente de la educación básica y, más específicamente, de la educación primaria en los países de desarrollo. El primer crédito educativo lo concedió a Túnez en África, para educación secundaria en 1963 y desde entonces y hasta 1990, el Banco había concedido créditos por cerca de 10 billones de dólares, e intervino en 375 proyectos educativos en 100 países del mundo (Coraggio, 1997, p. 79).

Aunque en 1973, el entonces presidente del BM, Robert Mc Namara anunció un viraje radical en la política de este organismo -el BM focalizaría su acción en los más pobres- y se da entonces un incremento fuerte y sostenido en educación primaria. Dicho énfasis sobre la escuela primaria, se ha visto reforzado a raíz de la Conferencia Mundial "Educación para Todos" realizada en Joutien, Tailandia en el mes de marzo de 1990, convocada conjuntamente con otros organismos especializados componentes del Sistema de las Naciones Unidas -UNESCO, UNICEF, PNUD-, la cual definió la educación básica como la 
prioridad para la presente década y la educación primaria como "punta de lanza" (Coraggio, 1997, p. 80) $)^{14}$.

Algunos podrán objetar que la enseñanza primaria universal, es una meta irrealizable e inasequible. En realidad, para lograr que se instituya la enseñanza primaria universal en un plazo de diez años en todas las regiones en vías de desarrollo, se necesitarían sólo entre 7.000 y 8.000 millones de dólares anuales adicionales. Esto equivale a aproximadamente el costo de cuatro días de gasto militar en el mundo; siete días de especulación monetaria en mercados internacionales; menos de la mitad de lo que los padres norteamericanos invierten todos los años en juguetes para sus hijos; y menos de lo que los europeos gastan cada año en juegos de computadora o agua mineral (Programa Internacional de Becas, 2000, p. 337).

Una vez expuestos los principales paralelismos sobre el interés en la educación primaria por parte del BM, nos interesa correlativamente establecer la naturaleza de este derecho en comparación y a la luz de lo normado en los diferentes instrumentos internacionales. Inicialmente, debemos decir que, en el marco del vigésimo período de sesiones del Comité de Derechos Económicos, Sociales y Culturales de la Organización de las naciones Unidas, realizado en el año de 1999, se emitió la observación general número 11, denominada "Planes de Acción para la enseñanza primaria" (Artículo 14 Pacto Internacional de Derechos Económicos, Sociales y Culturales). El citado artículo 14 de Pacto Internacional de Derechos Económicos, Sociales y Culturales (PIDESC), exige a los estados partes que aún no hayan podido instituir la enseñanza primaria obligatoria y gratuita, que se comprometan a elaborar y adoptar, dentro de un plazo de dos años, un plan detallado. Al respecto, el citado artículo contiene diversos elementos que deberían ser ampliados a la luz de la amplia experiencia adquirida por el Comité, entre los que podemos destacar la obligatoriedad, la gratuidad y las obligaciones. Sobre el primer punto, ha entendido dicha obligatoriedad como "No optativa", por lo que el elemento de obligatoriedad sirve para destacar el hecho de que ni los padres ni los tutores, ni el Estado, tienen derecho a tratar como optativa la decisión de si el niño debería tener acceso a la enseñanza primaria (Programa Internacional de Becas, 2000, p. 353).

El segundo aspecto o gratuidad, se refiere a que el derecho se formula de manera expresa para asegurar la disponibilidad de enseñanza primaria gratuita para el niño. Los derechos de matricula impuestos por el Gobierno, las autoridades locales o la escuela, así como otros costos directos, son desincentivos del disfrute del derecho que pueden poner en 
peligro su realización. Por último, en lo concerniente a las obligaciones, tenemos que el estado parte no puede eludir la obligación inequívoca de adoptar un plan de acción, alegando que no dispone de los recursos necesarios (Programa Internacional de Becas, 2000, p. 354).

Al respecto, nos encontramos con que el Pacto Internacional de Derechos Económicos, Sociales y Culturales (PIDESC), en el artículo 13, párrafo primero aduce que la educación debe orientarse hacia el sentido de la "dignidad personal", y enumera que la educación "debe capacitar a todas las personas para participar efectivamente en una sociedad libre" 15 .

El párrafo segundo se refiere a la manera en que debe implementarse el ejercicio del derecho a la educación. En este punto nos interesa destacar la forma en que se segmentan los diferentes tipos de enseñanza y cómo deben implementarse por los respectivos estados adoptantes del convenio. Con respecto a la enseñanza primaria, esta "debe ser obligatoria y asequible a todos gratuitamente;" (inciso a). Se habla de tener "...en la medida de lo posible", una educación fundamental para aquellas personas que no hayan recibido o tomado el ciclo completo de instrucción primaria. Esta es la educación de adultos y los diferentes programas encaminados a alfabetizar y educar a aquellas personas mayores que, por uno u otro motivo no hayan podido cursar este tipo de enseñanza (inciso d). Al final, la norma llama a una serie de aspiraciones o tareas específicas: desarrollar activamente el sistema escolar en todos los ciclos de enseñanza; implementar un sistema adecuado de becas y mejorar continuamente las condiciones materiales del cuerpo docente (inciso e).

Analizando otra observación general del Comité de Derechos Económicos, Sociales y Culturales realizada en el mismo año de 1999, vamos a extraer consideraciones importantes en la Observación General número 13, denominada "El derecho a la educación". Aunque el documento es de suma importancia para los(as) estudiosos(as) en esta materia, nos interesa resaltar lo dicho por este Comité, en el Apartado (b) del párrafo 2 del artículo 13, referente a "El derecho a la enseñanza secundaria". Aduce que la enseñanza secundaria comprende los elementos de disponibilidad, accesibilidad, aceptabilidad y adaptabilidad que son comunes a la enseñanza en todas sus formas y en todos sus niveles y la implantación progresiva de la enseñanza gratuita" significa que, si bien los estados deben atender prioritariamente a la enseñanza primaria gratuita, también tienen la obligación de adoptar 
medidas concretas para implantar la enseñanza secundaria y superior gratuitas (Programa Internacional de Becas, 2000, p. 356).

En el párrafo décimo tercero, se establece lo siguiente:

De conformidad con el apartado b) del párrafo 2 del artículo 13, la enseñanza secundaria debe "ser generalizada y hacerse accesible a todos, por cuantos medios sean apropiados $\mathrm{y}$, en particular, por la implantación progresiva de la enseñanza gratuita". La expresión "generalizada" significa, en primer lugar, que la enseñanza secundaria no depende de la aptitud o idoneidad aparentes de un alumno y en segundo lugar, que se impartirá en todo el Estado de forma tal que todos puedan acceder a ella en igualdad de condiciones. (Organización de las Naciones Unidas, 2001, p. 86)

Ahora bien, sobre el valor de la educación especializada/técnica, en la Declaración Universal de Derechos Humanos se afirma que "la instrucción técnica y profesional habrá de ser generalizada". De acuerdo con la observación general que estamos escudriñando, el derecho a la enseñanza técnica y profesional abarca los siguientes aspectos:

a) Capacita a los estudiantes para adquirir conocimientos y competencias que contribuyan a su desarrollo personal, su posibilidad de valerse por sí mismos y acrecienta la productividad de sus familias y comunidades, comprendido el desarrollo social y económico del Estado Parte; b) Tiene en cuenta las circunstancias sociales, culturales y educativas de la población en cuestión; las competencias, los conocimientos y los niveles de calificación necesarios en los diversos sectores de la economía; y el bienestar, la higiene y la seguridad laborales; c) Se ocupa de reciclar a los adultos cuyos conocimientos y competencias hayan quedado atrasados a causa de las transformaciones tecnológicas, económicas, laborales, sociales, etc; d) Consiste en programas que den a los estudiantes, especialmente a los de los países en desarrollo, a la posibilidad de recibir enseñanza técnica y profesional en otros estados, con vistas a una transferencia y una adaptación de tecnologías correctas. (Organización de las Naciones Unidas, 2001, p. 86)

La tendencia del BM para definir que se entiende por educación básica, transita por varias fases o episodios históricos. En ese sentido, volviendo a hacer mención de ROSA MARÍA TORRES, tenemos que la autora nos enuncia que en el primer estudio regional Volumen 5, Número 2, Año 2005, ISSN 1409-4703 
elaborado por esta instancia sobre el sector educativo -años ochenta-, el término educación básica se reservaba solamente para la educación no-formal de jóvenes y adultos, y se refería a la adquisición de los rudimentos de la lectura, la escritura y el cálculo. Posteriormente y hasta principios de los años 90 , este tipo de educación pasó a ser equivalente a educación primaria. En el documento de política (1996), se denomina como educación básica a la educación primaria más el primer ciclo de la educación secundaria; estimándose que "los conocimientos, capacidades y actitudes esenciales para funcionar eficazmente en la sociedad" (BM, 1996, p. 107) se adquieren en el aparato escolar y que dicha adquisición requiere aproximadamente ocho años de instrucción (Coraggio, 1997, p. 86).

Precisamente, para ese año de 1996, el BM emite una posición en torno a su papel en el ámbito de la educación, al aducir lo siguiente:

La difusión de la educación ha reducido la pobreza al contribuir a que las economías de los países en desarrollo crezcan a ritmos sin precedentes. Sin embargo, siguen habiendo todavía muchos problemas por resolver: ampliar el acceso en algunos países, y en muchos otros, aumentar la equidad, mejorar la calidad de la educación y acelerar el ritmo de la reforma educacional. Los sistemas actuales de financiamiento y de gestión no son con frecuencia educados para hacer frente a esos problemas. El gasto público en educación es muy a menudo ineficiente y poco equitativo. Dada la competencia para obtener fondos públicos y la presión sobre esos fondos, se necesitan nuevas fuentes de financiamiento. Además, es probable que se necesiten también cambios en la organización y la gestión de los sistemas de educación para permitir la flexibilidad y las posibilidades de elección que contribuyen a mejorar el rendimiento y las perspectivas de los estudiantes. (Banco Mundial, 1996, pp. 6-7).

La posibilidad de cambio en los patrones educativos, es muy reducida. Incluso si se habla de resolver problemas estructurales que presentan nuestras economías, hay que hacer notar que el BM define un conjunto de "avenidas promisorias" y "callejones sin salida" para reformar, por ejemplo, la escuela primaria. Es así, cómo prioriza el libro de texto (alta incidencia y bajo costo) sobre el docente (alta incidencia y alto costo); o la formulación de textos y estudios provenientes de especialistas mayormente de corte anglosajón, sobre lo que tengan que decir los expertos de América Latina, con mayor conocimiento regional y político de la realidad (Coraggio, 1997, pp. 103-104). 


\section{Consideraciones Finales}

Una vez expuesto el transitar tan amplio que conlleva la naturaleza de la educación, nos permitimos esbozar algunas consideraciones a título de epílogo:

La educación encierra una veta de movilidad y ascenso social basada en la revolución que produce el conocimiento. Sin embargo, los aparatos ideológicos del Estado utilizan la educación desde una óptica de mantenimiento del statu quo, y distan mucho de poder enarbolar tesis revisionistas de la realidad cotidiana. Lo anterior es así, debido a que el proceso educativo no es un elemento neutro, y se encuentra retroalimentado de una serie de factores que confluyen para su implementación: medio social; cultural; lingüístico etc. Es por esta razón, que no se puede hablar de un modelo educativo único o estandarizado, aunque las tendencias de los organismos especializados es más bien a homogenizar un solo nivel educativo para todos los países en desarrollo.

En relación con lo expuesto en el párrafo anterior, el derecho a la educación no se termina en la educación primaria, como lo quiere hacer notar el Banco Mundial, sino que cómo lo hemos expuesto: abarca otras fases de educación secuenciada y hasta superior, según se desprende de los mismos instrumentos internacionales y de las observaciones de expertos. Más bien la educación primaria es el acceso o llave de ingreso a la educación diversificada, técnica, secundaria y hasta superior, por lo que no es posible hablar de que el derecho a la educación, es solamente una etapa primaria. Su función es servir de eslabón para avanzar hacia otros estadios del conocimiento y la superación personal, educación primaria no puede ser un fin en si misma.

Por otra parte, tenemos que la educación visualizada desde la óptica de las instancias internacionales -incluso de ámbitos propios en derechos humanos como lo hemos visto-, impone sendos deberes que implican una actividad estatal de primer orden. Se habla de aspectos tales como obligatoriedad, extensión, accesibilidad y recursos materiales para invertir, con el firme propósito de fecundizar el derecho a la educación. Ello exige sin duda alguna, una postura política de primer orden, con decisiones que inciden en el desarrollo educativo, a través de obligaciones de hacer.

En contrapartida y como paliativo ideológico/político, se gestan corrientes conservadoras que apuestan a reducir precisamente, el accionar de los entes estatales en espacios y ámbitos que consideran, pueden ser ejecutados por los particulares. En este 
contexto, el Estado no debe acceder a ninguna demanda o petición interna que llega a su centro de poder decisorio -imputs-, por lo que se apuesta más al entorno internacional que a las capacidades endógenas. Así las cosas, la educación y los gastos ascendentes que ésta conlleva en términos de presupuesto interno, son vistos como poco deseables para una óptica economicista, que reduce todo el análisis a este nivel.

La concepción de educación del Banco Mundial, se queda rezagada en torno a la intencionalidad de propender a cumplir la máximo de que existirá correlativamente, un mayor desarrollo en nuestros países del tercer mundo a mayor nivel de educación. De hecho, para algunos autores, la razón de ser del Banco Mundial hay que encontrarla en la necesidad de concebir instrumentos necesarios para la reconstrucción y estabilización de las economías europeas dislocadas por la guerra. Con el advenimiento de la guerra fría, las tareas del sistema de Bretton Woods se orientaron con mayor fortalecimiento del bloque occidental y al desarrollo capitalista del Tercer Mundo (Asmann, 1980, pp 107-108).

\section{REFERENCIAS}

Aguiar Aranguen A, et al. (1994). Estudios Básicos de Derechos Humanos. Tomo I. San José: INSTITUTO INTERAMERICANO DE DERECHOS HUMANOS.

ALVAREZ, F. (1989). Cinco Lecciones sobre el Humanismo. San José: Editorial Universidad Estatal a Distancia, EUNED.

ALTHUSSER, L. (1987). Ideología y Aparatos Ideológicos del Estado. $7^{a}$ ed. México: Ediciones Quinto Sol.

ARRIÉN, JB. (1997). Calidad de la Educación en el ISTMO Centroamericano. San José. UNESCO.

ASSMANN, H. (ed). (1980). El Banco Mundial : Un Caso de Progresismo Conservador. San José: Departamento Ecuménico de Investigaciones.

BANCO MUNDIAL. (1996). Prioridades y estrategias para la educación: Examen del Banco Mundial. Washington: Banco Mundial.

BROUDY, HS. (1966). Una Filosofía de la Educación. México: Editorial Limusa-Wiley.

BRUNER, J. (1987). La importancia de la Educación. Ediciones Piados, Barcelona, Buenos Aires, México, primera edición.

CARVAJAL VILLAPLANA, A. (1999). Los Derechos Humanos y la Cultura. Revista de Filosofía de la Universidad de Costa Rica. 36 (90): 509-525. 
COLOM, A. (2000). Desarrollo Sostenible y educación para el Desarrollo. Barcelona: Octaedro.

Comisión Económica para América Latina y El Caribe (CEPAL). (1997). La Igualdad de los Modernos: reflexiones acerca de la realización de los derechos económicos, sociales y culturales en América Latina. San José, Costa Rica: Instituto Interamericano de Derechos Humanos.

CORAGGIO, JL. y TORRES, RM. (1997). La Educación según el Banco Mundial: Un Análisis de sus propuestas y métodos. Argentina: Editorial Darla.

CURLE, A. (1977). Educación Liberadora. Barcelona: Editorial Herder.

CHACON MATA, AM. (1996). Gobernabilidad y derechos humanos. En Semanario "Esta Semana", del 10 al 16 de abril de 1996.

DENGO, ME. (1995). Educación Costarricense. San José Costa Rica: Editorial Universidad Estatal a Distancia.

DUVERGER, M. (1976). Introducción a la Política. Barcelona: Editorial Demos.

FAINHOLK, B. (1979). Introducción a la Sociología de la Educación. Buenos Aires: Editorial Humanitas.

FARRIER BRAIS, P; LOBO QUIRÓS, VM; y PEÑARANDA SEGREDA, GA. (1988). Los Derechos Económicos, Sociales y Culturales en el Protocolo Adicional a la Convención Americana de Derechos Humanos (Pacto de San José). Tomos I, II, III y IV. San José, Seminario de Graduación para optar al título de Licenciados en Derecho, Facultad de Derecho de la Universidad de Costa Rica.

FAURE, E y otros. (1978). Aprender a Ser: la educación del futuro. $7^{\mathrm{a}}$. ed. Madrid: Alianza/Unesco.

HUBERT, R. (1959). Tratado de la Pedagogía General. 3ª. ed. Argentina: Editorial Ateneo.

INSTITUTO INTERAMERICANO DE DERECHOS HUMANOS. (1996). Estudios Básicos de Derechos Humanos. Tomo V. San José: El Instituto.

KAHN, J.J. (1976). El Concepto de Cultura: Textos Fundamentales. Barcelona: Editorial Aragrana.

KÜNNERMAN, R. (1996). The Right to an Adequate Standart of Living. International Institute of Human Rights. Lecture 2, p. 2, $1-26$ july 1996, $27^{\text {th }}$ Study Sesion Strasbourg-France.

LAMONT, C. (1956). El Humanismo como una Filosofía. Buenos Aires: Editorial Claridad.

LÓPEZ AVENDAÑO, O. (1997). Sociología de la Educación. 2a reimp. San José: Editorial Universidad Estatal a Distancia. 
MALAVASSI VARGAS, G. (1973). Humanismo. San José: Cátedra de Filosofía, Universidad de Costa Rica.

MINISTERIO DE EDUCACIÓN PÚBLICA DE COSTA RICA. (1993). Mejoramiento de la Calidad de la Educación Centroamericana. San Carlos, Costa Rica: El Ministerio.

MONGE NAJERA, J. (ed.). (1994). Desarrollo Sostenible. La Visión desde Los Países Menos Industrializados. San José: EUNED, Universidad Estatal a Distancia.

ORGANIZACIÓN DE LAS NACIONES UNIDAS. (1995). ABC de las Naciones Unidas. Departamento de Información Pública. Nueva York: ONU.

ORGANIZACIÓN DE LAS NACIONES UNIDAS. (2001). Instrumentos Internacionales de Derechos Humanos. General HRI/GEN/1/Rev.5 del 26 de abril del 2001, versión en español.

ORTEGA y GASSET, J. (1959). La Rebelión de las Masas. Madrid: Editorial Revista Occidente.

PASSMORE, J. (1978). La Responsabilidad del Hombre frente a la Naturaleza. Madrid: Alianza Universidad S.A.

PECES-BARBA MARTíNEZ, G.; FERNÁNDEZ GARCÍA, E. y DE ASÍS ROIG, R. (2002). EI Contexto Social y Cultural de los Derechos, los Rasgos Generales de Evolución. Tomo II, Volumen I. Madrid: Editorial Dikynson.

PETERS, RJ. (1995). ¿En qué consiste el proceso Educacional? En El Concepto de Educación. Buenos Aires: Editorial Piados.

ROBERTSON, R.E. (1994). Measuring State Compliance with the Obligation to Devote the "maximun available resources" to Realizing Economic, Social and Cultural Rights. En Human Rights Quarterly. 16(4): 693-694.

ROSENTAL, M. e IUDIN, P. (1988). Diccionario Filosófico. Argentina: Ediciones Universo.

SALINAS, P. (1974). Aprecio y Defensa del Lenguaje. Puerto Rico, San Juan: Editorial Universidad de Puerto Rico, San Juan.

SAVATER, F. (1997). El Valor de Educar. 8 $^{\mathrm{a}}$. ed. Barcelona: Editorial Ariel S.A.

SEGURA, O. (comp.). (1992). Desarrollo Sostenible y Políticas Económicas en América Latina. San José: DEl.

SEPULVEDA, S. y EDWARDS, R. (1995). Desarrollo Sostenible: Agricultura, Recursos Naturales y Desarrollo Rural. Desarrollo Rural Sostenible. Tomo 5. San José: Instituto Interamericano de Ciencias Agrícolas y BMZ/GTZ. 
SOTO, W. (1985). Crisis económica y dominación ideológica: el papel del medio difusor en la articulación de la clase dominante costarricense. En Revista de Ciencias Sociales, (30), 77-88.

TORRES, CA. (2001). Democracia, Educación y Multiculturalismo. México: Siglo veintiuno.

UNESCO-CEPAL.PNUD. (1984). La educación popular en América Latina. Biblioteca de Cultura pedagógica, Serie Educación y Sociedad.

UNESCO. (1996). La educación encierra un tesoro. Informe a la Unesco de la Comisión Internacional sobre la educación para el siglo XXI, preparado por JACQUES DELORS, Madrid: Ediciones UNESCO.

VALLE LABRADA, R. (2000). La Dignidad del Hombre y el Ejercicio de los Derechos Humanos. ANUARIO DE DERECHOS HUMANOS. Instituto de Derechos Humanos, Facultad de Derecho, Universidad Complutense. Madrid: Nueva Época.

2 PETERS, (R.J), ¿En qué consiste el proceso Educacional?, en "El Concepto de Educación", Buenos Aires, Editorial Piados, 1995. "El concepto de educación, no se refiere a ningún proceso particular; más bien contiene referencias a los criterios que deben ajustarse determinados procesos. Se parece, en este sentido, al concepto de reforma, que tampoco designa un proceso particular (...) Los conceptos de "reforma" y "educación" encuentran aplicación correcta si estos procesos satisfacen ciertos criterios. "Educación" y "reforma" no son piezas del mobiliario en el mundo de la mente; son, más bien, etiquetas de aprobación que indican que algunos muebles alcanzan ciertos estándares" pág 14.

Este tipo de aprendizaje, que tiende menos a la adquisición de conocimientos clasificados y codificados que al dominio de los instrumentos mismos del saber, puede considerarse a la vez medio y finalidad de la vida humana. En cuanto medio, consiste para cada persona en aprender a comprender el mundo que la rodea, al menos suficientemente para vivir con dignidad, desarrollar sus capacidades profesionales y comunicarse con los demás. Como fin, su justificación es el placer de comprender, de conocer, de descubrir, en UNESCO, "La educación encierra un tesoro", Informe a la Unesco de la Comisión Internacional sobre la educación para el siglo XXI, preparado por JACQUES DELORS, Ediciones Unesco, Madrid, 1996, pp. 96-97.

${ }^{4}$ Aprender a conocer y aprender a hacer son, en gran medida, indisociables. Pero lo segundo está más estrechamente vinculado a la cuestión de la formación profesional: ¿cómo enseñar al alumno a poner en práctica sus conocimientos y, al mismo tiempo, cómo adaptar la enseñanza al futuro mercado de trabajo, cuya evolución no es totalmente previsible? (...), Ibíd., pág 99.

5 Sin duda este aprendizaje constituye una de las principales empresas de la educación contemporánea. Demasiado a menudo, la violencia que impera en el mundo contradice la esperanza que algunos habían depositado en el progreso de la humanidad. La historia humana siempre ha sido conflictiva, pero hay elementos nuevos que acentúan el riesgo, en particular el extraordinario potencial de autodestrucción de la humanidad misma ha creado durante el siglo XX. (...)

¿Cómo mejorar esta situación? La experiencia demuestra que, para disminuir ese riesgo, no basta con organizar el contacto y la comunicación entre miembros de diferentes grupos. Por el contrario, si esos grupos compiten unos con otros o no están en una situación equitativa en el espacio común, ese tipo de contacto puede agravar las tensiones latentes y degenerar en conflictos. En cambio, si la relación se establece en un contexto de igualdad y se formulan objetivos y proyectos comunes, los prejuicios y la hostilidad subyacente pueden dar lugar a una cooperación más serena e, incluso, a la amistad. 
Parecería entonces adecuado dar a la educación dos orientaciones complementarias. En el primer nivel, el descubrimiento gradual del otro. En el segundo, y durante toda la vida, la participación en proyectos comunes, un método quizá eficaz para evitar o resolver los conflictos latentes", UNESCO, "La educación encierra un tesoro", pp. 103-104.

${ }_{7}^{6}$ Ibíd, pp 106-108.

${ }^{7}$ Ibíd, pág 95

${ }^{8}$ Ahora bien, el Informe Bruntland, denominado "Nuestro Futuro Común", dentro del marco de la Comisión Mundial de Ambiente y Desarrollo en 1987, habla por primera vez del concepto de Desarrollo Sostenible: "El desarrollo sostenible es un proceso de cambio en el cual la explotación de los recursos, la orientación de las inversiones y del desarrollo tecnológico y el cambio institucional están en armonía y mejoran el potencial corriente y futuro para satisfacer las necesidades humanas. El concepto supone límites que se imponen a los recursos del medio ambiente, el estado actual de la tecnología y de la organización social y la capacidad de la biosfera para absorber los efectos de las actividades humanas, pero tanto la tecnología como la organización social pueden ser ordenadas y mejoradas de manera que abran el camino a una nueva era de crecimiento económico" Para el Dr. RONNIE de CAMINO, "...hay que considerar de la definición del Informe Bruntland,; -que hay que cambiar la manera como hacemos las cosas, si bien nadie parece todavía tomar este mensaje suficientemente en serio; -que los cambios deben ser en las tasas de explotación de los recursos, en la asignación de recursos económicos y en los objetivos de estas inversiones (tendencia exagerada al lucro), en las tecnologías y en las instituciones de cualquier nivel. Es decir, las tasas de explotación, los objetivos de los inversionistas, los métodos de explotación y las formas de organización actuales deben ser cuestionadas en todos los recursos naturales (...); -que el cambio tecnológico es importante, pues puede aumentar la capacidad de un sistema y su capacidad de carga, aunque no es la única solución y la tecnología no es la panacea" CAMINO de, (Ronnie) en SEGURA, (OIman) comp. "Desarrollo Sostenible y Políticas Económicas en América Latina", San José, DEI, primera edición, 1992, pág. 176.

${ }^{9}$ Ver en igual sentido a PASSMORE, (John) "La Responsabilidad del Hombre frente a la Naturaleza", Alianza Universidad S.A., Madrid, 1978.

${ }_{11}^{10}$ Véase Infra págs 30-31.

${ }^{11}$ Se refieren básicamente al respeto de la libertad de los padres y tutores de escoger escuelas distintas para sus hijos o pupilos de las creadas por las autoridades públicas, siempre que aquéllas satisfagan las normas mínimas de enseñanza

${ }_{12}$ Con respecto a la noción de "contenido mínimo", se ha gestado una evolución sumamente valiosa al respecto. Tomemos en consideración la exposición siguiente por parte del Profesor ALSTON: "el hecho de que dicho contenido básico debe existir (,...) parecería una consecuencia lógica del uso de la terminología de los derechos. En otras palabras, no habría justificación para elevar una "reclamación" a la condición de un derecho (con todas las connotaciones que este concepto presuntamente tiene) si su contenido normativo puede ser tan indeterminado que permita la posibilidad de que los que ostentan los derechos no posean ningún derecho particular a nada. Por lo tanto, cada derecho debe dar lugar a un derecho mínimo absoluto, (SUBRAYADO NUESTRO) en ausencia del cual deberá considerarse que un Estado parte viola sus obligaciones", citado por CEPAL (Comisión Económica para América Latina y El Caribe), "La lgualdad de los Modernos : reflexiones acerca de la realización de los derechos económicos, sociales y culturales en América Latina", Instituto Interamericano de Derechos Humanos, San José -Costa Rica, 1997, pp 39-40. Un interesante relato en torno a la evolución del concepto de contenido mínimo, es realizado por ANTONIO CANCADO TRINDADE, el cual exponemos a continuación: "En los debates de 1990 del Comité de Derechos Económicos, Sociales y Culturales de Naciones Unidas, se insistió en el "Contenido Mínimo" de estos derechos, afectados por los problemas de la deuda, de los ajustes estructurales y del empobrecimiento. Los debates de 1991 del Comité se concentraron en los problemas de la utilización de indicadores económicos y sociales (en razón de su insuficiencia para asistir el trabajo del Comité), habiendo concluido que dichos indicadores deberían buscar un equilibrio entre los conceptos de cantidad y sobre todo de calidad, para mejorar reflejar la realidad de los derechos humanos. El Informe del comité sobre su sexta sesión indica que, también en 1991, se procedió a la elaboración de directrices revisadas sobre los informes gubernamentales, de modo que 
contengan, inter alia, informaciones sobre indicadores económicos y sociales e indicaciones sobre el estándar de vida no solo de la sociedad como un todo pero también de determinados grupos, particularmente los vulnerables(...)" CANCADO TRINDADE, (Antonio), "La Protección Internacional de los Derechos Económicos, Sociales y Culturales", en "Estudios Básicos de Derechos Humanos", Vol I, Op Cit, pág 57. Para el período 1989-1991, el Comité de DESC, elaboró y divulgó cuatro "comentarios generales"; el primero del año 1989 es dedicado al perfeccionamiento del sistema de informes por los Estados Partes bajo el Pacto, de modo que fuese factible una mejor evaluación del progreso en relación con los DESC. En el Comentario general No 2 de 1990, el Comité sugirió medidas de asistencia técnica internacional para dichos derechos, basados en el artículo 22 del PIDESC. Pero fue el Comentario General No 3 de 1990, en donde el Comité insistió en las "obligaciones mínimas", de todos los Estados Partes de asegurar al menos, la satisfacción de niveles esenciales mínimos de cada uno de los derechos consagrados en el Pacto (lbíd. pág 58). Sigue entonces aduciendo párrafo 57 de la Observación General No 13, lo siguiente: "En su Observación General No 3, el Comité confirmó que los Estados Partes tienen "una obligación mínima de asegurar la satisfacción de, por lo menos, niveles esenciales de cada uno de los derechos" enunciados en el Pacto, incluidas las "formas más básicas de enseñanza". En el contexto del artículo 13, esta obligación mínima comprende: el velar por el derecho de acceso a las instituciones y programas de enseñanza públicos sin discriminación alguna; por que la enseñanza corresponda a los objetivos expuestos en el párrafo 1 del artículo 13; proporcionar enseñanza primaria a todos, de conformidad con el apartado a) del párrafo 2 del artículo 13; adoptar y aplicar una estrategia nacional de educación que abarque la enseñanza secundaria, superior y fundamental; y velar por la libre elección de la educación sin la intervención del Estado ni de terceros, a reserva de la conformidad con las normas mínimas en materia de enseñanza (párrafos 3 y 4 del artículo 13)".

${ }^{13}$ Esta postura es la pregonada por el pensamiento marxista. Según Marx la estructura de toda sociedad está constituida por "niveles" o "instancias" articuladas por una determinación específica: la infraestructura o base económica ("unidad de fuerzas productivas y relaciones de producción"), y la superestructura que comprende dos "niveles" o "instancias": la jurídico-política (el derecho y el Estado) y la ideología (las distintas ideologías, la religiosa, moral, jurídica, política y entre estas la educación.

14 Cfr: En particular, los principales promotores de la iniciativa a favor de la Educación para Todos (PNUD, UNESCO, UNICEF, Banco Mundial) declaran comprometerse a apoyar los sectores prioritarios de acción internacional que se indican más adelante y adoptar las medidas adecuadas para alcanzar los objetivos de la Educación para Todos, cada uno de ellos en el marco de su respectivo mandato y de sus responsabilidades especiales y de acuerdo con las decisiones de sus órganos de dirección., UNESCO, "Estadísticas e indicadores de la Educación 1998/99: (...)", Op Cit pág 19.

${ }_{15}^{15}$. Nos inclinamos a pensar que esta connotación de sociedad libre debe verse dentro de la coyuntura postguerra mundial, época que fue redactado el Pacto y sobre todo dentro de un período denominado como "Guerra Fría". Con el advenimiento del bloque socialista encabezado por la potencia de la Unión Soviética y sus aliados por un lado, y el bloque del oeste cuyo país rector lo fue Estados Unidos y el bloque de Europa occidental, se suscita un enfrentamiento en todos los ordenes: ideológico/económico/político etc. 